\title{
Scale, Technique and Composition Effects in Manufacturing $\mathrm{SO}_{2}$ Emissions
}

\author{
Jean-Marie Grether • Nicole A. Mathys · Jaime de Melo
}

Received: 10 December 2007 / Accepted: 20 September 2008 / Published online: 17 October 2008

(C) Springer Science+Business Media B.V. 2008

\begin{abstract}
Combining two data sources on emissions with value-added and employment data, this paper constructs six data bases on sulfur dioxide $\left(\mathrm{SO}_{2}\right)$ intensities that vary across countries, sectors and years. This allows us to perform a growth decomposition exercise where the change in world manufacturing emissions is decomposed into scale, composition and technique effects. The sample covers the period 1990-2000, and includes 62 countries that account for $76 \%$ of world-wide emissions. While manufacturing activity has increased by a rough $10 \%$ (scale effect), we estimate that emissions have fallen by about $10 \%$, thanks to the adoption of cleaner production techniques (the technique effect) and a small shift towards cleaner industries (between-sector effect). As output and productivity gains have been biased towards large emerging countries like China and India, which are both clean in terms of emissions per unit labor and dirty in terms of emissions per dollar, the sign and magnitude of the between-country effect depends on the choice regarding the scaling factor ( $-2 \%$ for employment, $+25 \%$ for value-added, with a corresponding adjustment of the technique effect). The paper also shows that these estimates are robust to changes in aggregation across entities (regions or countries) and across industries, and that composition changes are correlated with changes in prices and trade intensities.
\end{abstract}

Keywords Manufacturing activities · Bottom-up approach $\cdot \mathrm{SO}_{2}$ emissions

Electronic supplementary material The online version of this article (doi:10.1007/s10640-008-9237-5) contains supplementary material, which is available to authorized users.

J.-M. Grether ( $\varangle)$

University of Neuchâtel, Pierre-à-Mazel 7, CH-2000, Neuchâtel, Switzerland

e-mail: jean-marie.grether@unine.ch

N. A. Mathys

University of Neuchâtel, Neuchâtel, Switzerland

N. A. Mathys

Swiss Federal Office of Energy, Bern, Switzerland

J. de Melo

University of Geneva, CERDI and CEPR, Geneva, Switzerland 


\section{JEL Classification Q56}

\section{Introduction}

It has long been recognized that our understanding of the relationship between the economy and the environment is limited by data availability, notably with respect to the growthenvironment nexus. Although very generally accepted, in empirical and theoretical discussions, the scale, composition and technique effects have failed so far to materialize into robust, let alone stylized facts (see e.g. Grossman and Krueger (1991) for an early application and the recent survey by Brock and Taylor (2005) for extensive discussion in growth models). In the absence of emissions linked to human activity - the so-called emission intensities used in the bottom-up approach-researchers have used average concentrations (e.g. Antweiler et al. (2001)) or total emissions per capita (Cole and Elliott 2003) in panel aggregate emission growth regressions. As a result, the respective role of composition effects within and across countries identified in the literature, have been obfuscated. Thus, whether there has been a shift towards "dirty" activities or "dirty" countries has largely remained elusive even for $\mathrm{SO}_{2}$ emissions which have desirable characteristics for studying compositional shifts and more generally the growth-environment nexus (strong local effects, a by-product from goods production, existing abatement technologies and differences in per-unit emissions across industries).

The Emission Database for Global Atmospheric Research (henceforth EDGAR, for more details see Olivier and Berdowski (2001)) gives information on emissions for several pollutants across sectors for 3 years $(1990,1995$ and 2000) and provides a starting point for relating more systematically the scale of economic activity in different sectors with emissions when it is combined with the more disaggregated data set of an earlier project, the Industrial Pollution and Projection System (IPPS, for details see Hettige et al. (1995)). We use these two data sources, along with national emissions over a large number of countries in Stern (2006) (hereafter STERN), to construct disaggregated data bases on emission across manufacturing sectors, countries and over time for sulfur dioxide $\left(\mathrm{SO}_{2}\right)$ emissions. Emission intensities by activity are then constructed by reconciliation with and extension of a recent Trade, Production and Protection (TPP) database (Nicita and Olarreaga 2007) resulting in a potential set of six databases that vary in terms of geographic (62 countries or 6 regions) and sectoral (7 or 28 sectors) disaggregation.

These data bases are then used to decompose changes in $\mathrm{SO}_{2}$ emissions into scale, composition and technique effects over the period 1990-2000. The overall picture that emerges is a world in which the increase in world manufacturing activity has been more than compensated by the decrease in world average emission intensity. The latter effect is further disentangled between composition and technique effects, and it turns out that the outcome depends on the scaling variable. When using employment, both effects work in the same direction, because there has been a (small) structural shift towards cleaner products and cleaner countries (i.e. with low emissions per employee) during the nineties. However, when using value-added as the scaling factor, composition and technique effects work in opposite directions because value-added has been reallocated towards low-productivity giants like China and India (which are dirty in terms of emissions per dollar) where productivity gains have also been larger. This leads to a sharper contrast between two large and opposite effects (positive for the between-country effect, negative for the technique effect), although the net impact (i.e. the addition of the two effects) is of course unaffected.

The remainder of the paper is organized as follows. Section 2 discusses the difference between emissions (most suitable to measure scale, technique and composition effects) and 
concentration estimates (most suitable for assessing the welfare implications of emissions) and presents a summary comparative review of the existing data sources for $\mathrm{SO}_{2}$ emissions by manufacturing industries. Section 3 details how the different data bases were constructed. Sections 4 and 5 are the heart of the paper. They present alternative decomposition formulas of the evolution of $\mathrm{SO}_{2}$ manufacturing emissions from 1990 to 2000 using several scaling factors and data bases. Section 6 explores the correlates behind the evolution of the composition effect. Section 7 concludes.

\section{Comparing $\mathrm{SO}_{2}$ Pollution Data}

This section discusses the appropriateness of emission and concentration data to study the effects of pollution. It then presents briefly the EDGAR database, the only available data base with time-varying emission data available on a disaggregated basis for a large sample of countries (full details on the data bases and construction of variables used in the paper are available in a separate appendix, any figure or table name starting with an "A" can also be found in this appendix available as supplementary material).

\subsection{Emissions or Concentrations}

Concentration data on sulfur dioxide in the air are probably the most appropriate indicator to assess the impact of pollution on the environment or on human health. However, they are very difficult to relate to economic activity and this for two basic reasons. First, although distance from emission sources is a fundamental determinant of concentration levels, sufficiently precise data on geographical locations of both production and observation sites are usually either fragmentary or missing altogether. This is one of the main obstacles to undertake convincing cross-country studies on the basis of concentration data. Second, even with a perfect knowledge of the location of human activities and of observation sites where concentration is measured, the relationship between the two is still a complex one because of the number of other factors that have to be controlled for. So, concentration levels are not only affected by non-human and non-industrial sources (e.g. volcanic activity or domestic heating), or by the type of measurement equipment; they also depend on weather conditions such as the wind speed, temperature, or rainfall at the site (rainfall typically reduces concentrations). Some of these effects are site-specific and can be controlled for with dummy variables (provided the sites do not change), while others, like weather-related effects, are time-varying and hence harder to control for.

To circumvent these difficulties, the alternative is to use emission rather than concentration data. By definition, emissions are directly linked to specific activities, and available data are suitable to analyze the production-pollution link both, on a large scale across countries, and at a reasonably disaggregated level. As this paper illustrates, this is particularly true regarding manufacturing emissions, which represent a substantial part of global man-made (i.e. anthropogenic) emissions in the case of $\mathrm{SO}_{2}$, and are especially policy-relevant since manufacturing activities can be the target of environmental, trade and industrial policies. Although sulphur dioxide emission inventories are collected in many countries, ${ }^{1}$ emissions are more difficult to measure than concentrations. This may generate differences in estimates between

1 For example the industrial pollution projection system (IPPS) in the US or the major air pollutants (MAP) emission inventory of the European Environment Agency. 
Table 1 Share of manufacturing sectors in world-wide $\mathrm{SO}_{2}$ emissions (\%)

\begin{tabular}{|c|c|c|c|c|c|}
\hline & EDGAR code & Name (ISIC rev. 2 code $^{\mathrm{a}}$ ) & 1990 & 1995 & 2000 \\
\hline 1 & F30 & Refineries, coke, gas $(353,354)$ & 7.74 & 7.43 & 7.17 \\
\hline 2 & $\mathrm{I} 10$ & Iron \& steel (371) & 0.57 & 0.59 & 0.66 \\
\hline 3 & $\mathrm{I} 20$ & Non-ferrous metals (372) & 12.26 & 12.92 & 14.94 \\
\hline 4 & $\mathrm{I} 30$ & Chemicals $(351,352)$ & 2.12 & 1.78 & 2.02 \\
\hline 5 & $\mathrm{I} 40$ & Building materials_cement (369) & 1.18 & 1.62 & 1.86 \\
\hline 6 & $\mathrm{I} 50$ & Pulp \& Paper (341) & 0.58 & 0.71 & 0.69 \\
\hline 7 & $\mathrm{~F} 10+\mathrm{B} 10$ & Fossil fuel and biofuel ${ }^{b}$ & 19.97 & 21.19 & 17.15 \\
\hline 8 & & Total manufacturing & 44.42 & 46.25 & 44.49 \\
\hline
\end{tabular}

a The correspondence with SIC codes is an approximation

${ }^{\mathrm{b}}$ To be ventilated across industrial sectors according to methodology described in Sect. 3

sources, depending on estimation techniques or assumptions with respect to production or abatement technologies. $^{2}$

\subsection{Manufacturing Emissions}

EDGAR is the unique source of time and country-varying emissions at a sufficiently disaggregated level to include several manufacturing sectors, opening the possibility to relate emissions to trade and economic structure. According to this data source, as shown in Table 1, manufacturing emissions represent about $45 \%$ of the world total during the 90 s.

Of the "six dirty sectors" listed in Table 1 (lines 1-6), the most polluting sectors are Non Ferrous Metals and Refineries. Close to half of manufacturing emissions is due to "fossil fuel and biofuel consumption", which is non-attributed across manufacturing sectors in the original EDGAR database. Section 3 proposes a method to allocate these fuel-based emissions across manufacturing sectors. Combining the resulting data with the TPP database leads to emission intensities estimates at a disaggregated level for the six polluting sectors identified here and a residual "clean" sector for a sample of 62 countries.

Unfortunately, there is no alternative data base against which to evaluate these constructed emissions. The best that can be done is to compare these estimates with those from the IPPS coefficients for the US in 1987, keeping in mind that our US estimates are for $1990 .^{3}$ This is done for emissions per dollar and for emissions per worker. Results of this comparison are displayed in Fig. 1.

Whichever data source is used, both emission intensities per worker and per dollar display enormous differences across sectors (note the use of log scales on the axis). Also the matching

\footnotetext{
2 Appendix 1 (in supplementary material) provides a detailed analysis of the correlations between concentration measures and different types of emission sources. On the one hand, we find that the correlation between concentrations and emissions is high at the world-wide level across the 1975-2000. However, this correlation is considerably weaker at the country level, because of differences of location between measurement stations and emission sources and because of the host of other factors that affect concentration levels and prove difficult to control for. On the other hand, there is a very strong correlation between national emissions reported by the two main data sources considered in this paper (EDGAR and STERN), but for the fact that EDGAR figures tend to be 10-20\% larger (because they control less for abatement activities) and exhibit an increasing trend at the world-wide level at the beginning of the nineties (while STERN data suggest the opposite). Both qualifications are discussed further below.
}

${ }^{3}$ Although US data are probably more reliable, a similar outcome was obtained with Chinese IPPS data. 

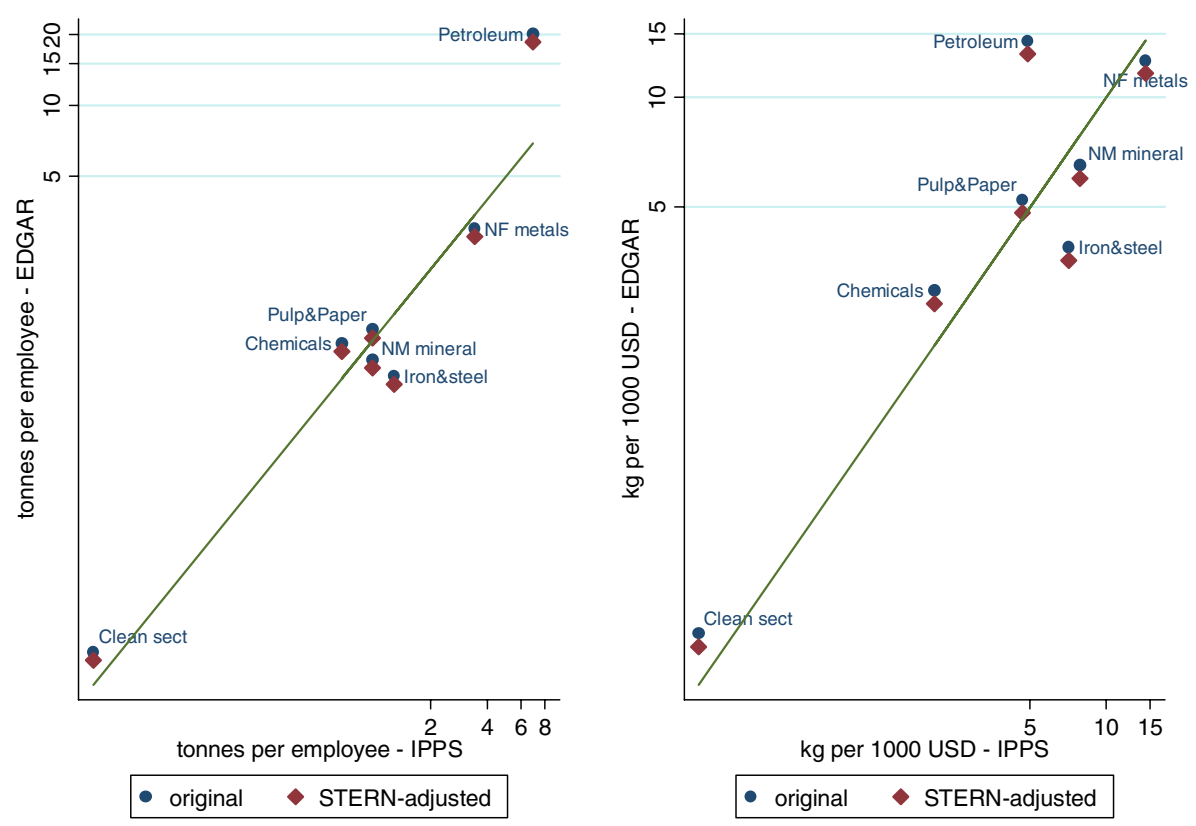

Fig. 1 IPPS versus EDGAR-derived emission intensities for the US (1987 for IPPS, 1990 for EDGAR)

between the two sets is far from perfect (the average absolute percentage difference is $52 \%$ for original EDGAR intensities and $46 \%$ for STERN-adjusted ones). This may be due to measurement errors, to differences in the time period (1990 for EDGAR, 1987 for IPPS) or to differences in sector classification. Adjusting for the above-mentioned overestimation of emissions by EDGAR data slightly increases the correspondence since the data are usually above the $45^{\circ} \mathrm{C}$ line. Though not obvious from the figure because of the scaling, note also that the matching is far better for emissions per employee than for emissions per USD since the sample correlation between the two sources of per employee intensities is equal to 0.94 and significant at $99 \%$, while it is non significant between per USD intensities. Overall, we conclude that EDGAR data should preferably be adjusted downwards using STERN total estimates and that per employee emissions tend to be more reliable than per USD emissions, at least for the US, an observation that is also confirmed across countries and regions in Fig. 2 and Table 3 below. These observations are taken into account in the construction of the data base presented in the next section.

\section{Constructing Manufacturing Emission Intensities}

We now detail the construction of a new and complete database reporting $\mathrm{SO}_{2}$ emissions for 7 manufacturing sectors in 62 developing and developed countries for 1990, 1995 and 2000 (the "base" years we refer to below). This emission data base is then combined with production and employment data in Sect. 4 to carry out a growth decomposition exercise into scale, composition and technique effects.

We proceed as follows. To construct the data base, we use two data sources on emissions [see detailed description in Appendix 2 (supplementary material)], one disaggregated across countries (EDGAR) and one across sectors (IPPS). EDGAR covers a large set of countries 
over three periods but only for six dirty industrial sectors, while IPPS provides emission intensities for 28 ISIC 3-digit sectors but only for the US, and for 1 year, $1987 .{ }^{4}$ Using the assumptions described below, data on industrial output and employment from the Trade Production and Protection (TPP) database (Nicita and Olarreaga 2007) were used to construct a set of six data bases on per dollar or per employee emission intensities (TPP data were completed by imputing missing values on the basis of the procedure described in Appendix 3 (in supplementary material) and by considering a 3-year moving average to control for cyclical fluctuations). These data bases were then scaled to match the total estimates of Stern (2006). We describe first the construction of the EDGAR-related data bases, then the IPPS-related data bases which serve as a check.

\subsection{EDGAR-Related Data Bases}

EDGAR data has two shortcomings. First, they do not take into account the fact that "clean" sectors also generate emissions. Second, they report an awkward non-imputed category, "fossil fuel and biofuel consumption" (F10 and B10), which represents about 45\% of total manufacturing emissions. Regarding emissions by the "clean" sectors, we rely on the IPPS data base (see below). For the non-imputed category, we carry out the following 3-step procedure:

(i) estimate the share of clean sectors in overall manufacturing emissions on the basis of IPPS coefficients applied to TPP employment data

(ii) apply this share to the total of EDGAR-based manufacturing emissions (imputed plus non-imputed categories), obtaining an estimate of "virtual" clean sectors emissions

(iii) substract the virtual amount from the non-imputed amount and spread the residual across dirty sectors according to the IPPS-derived share of each sector in dirty emissions. If the residual is negative, all unaffected emissions are allocated to the clean sectors. ${ }^{5}$

Steps (i) and (iii) imply that IPPS per employee intensities are assumed to be valid for every country and year, which is inaccurate but probably closer to reality than assuming that IPPS per dollar intensities are constant (see Sect. 3.2 for a discussion). Finally, all emissions are scaled so that total computed manufacturing emissions match the corresponding figure derived from Stern (2006). ${ }^{6}$ Emission intensities are obtained by dividing sectoral emissions by the corresponding employment or output figures provided by the TPP database. ${ }^{7}$

This is the first complete data base entered in the bottom left of Table 2. It is labeled EDGAR $_{\text {da }}$ (where subscript a(d) corresponds to aggregated (disaggregated), the first index referring to entities (countries or regions), the second to sectors) and covers 62 countries and 7 industrial sectors. For comparison purposes, these emission intensities have also been

\footnotetext{
4 Note that the IPPS data is even available at the 4-digit ISIC level, giving details for more than 80 manufacturing sectors. However, given that our economic activity database is reported at the 3-digit level we had to keep this level of aggregation.

5 Alternative procedures were also tested, either by using labor rather than emission shares in step (iii), or by skipping step (i) and directly splitting the non-imputed emissions among sectors. The selected procedure is the one that maximizes the sample correlation coefficient (at 0.94) between the 1987 US-IPPS intensities (our unique reference case) and the corresponding EDGAR-based intensities.

6 EDGAR-based manufacturing emissions shares are applied to Stern's 3-year moving average total estimates. For the majority of countries, the scaling factor is close to 0.9 [the interquartile range is between 0.8 and 1.0, with only a few outliers, see Fig. A8 (in supplementary material)].

7 For a limited number of cases where countries report positive emissions but zero employment for certain sectors, aggregation over sectors was applied.
} 
Table 2 Alternative databases on emission intensities

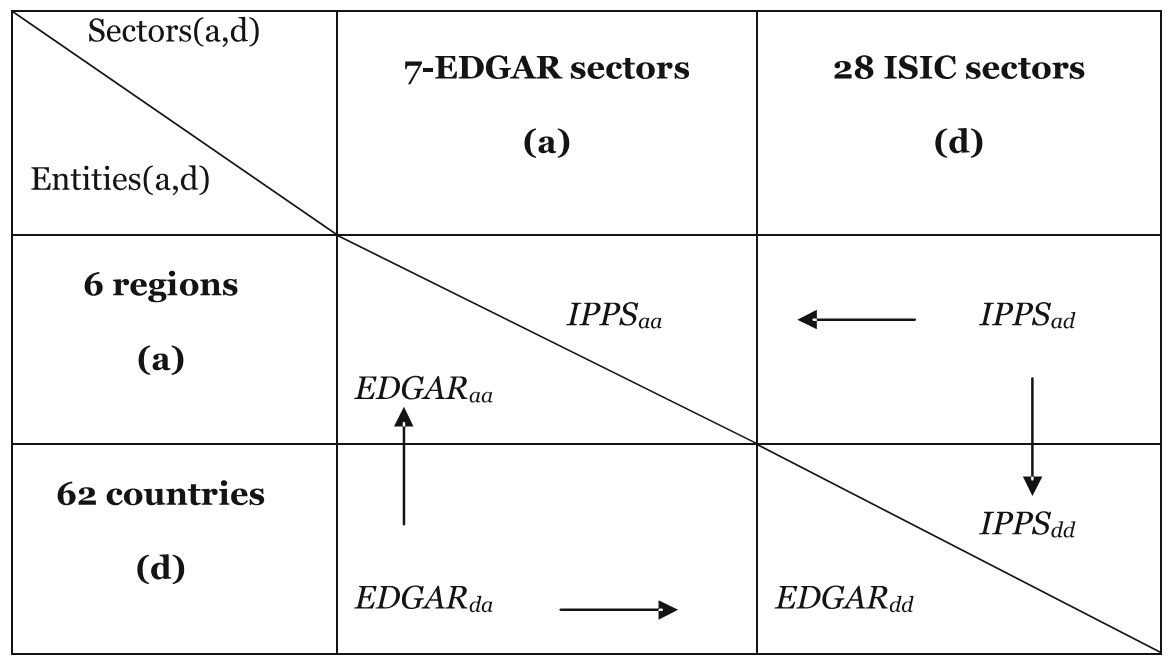

Notes: All data bases are available for the 3 years $(1990,1995,2000)$, and either in original levels (i.e. scaled to EDGAR totals for PPS-based data-see text) or scaled so that total manufacturing emissions match those reported by Stern (2006)

Subscript a(d) corresponds to aggregated (isaggregated), the first index referring to entities (regions or countries) the second to manufacturing sectors

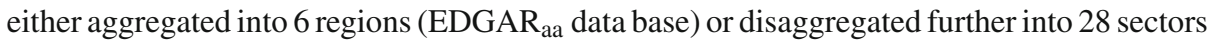
(EDGAR $\mathrm{dd}_{\mathrm{dd}}$ data base). The aggregation into regions is based on a definition of geo-economic regions that reflects both geographic proximity and similarity in income per capita (see Table A5 in supplementary material). The disaggregation procedure posits that the dispersion of intensities within each EDGAR category is identical to the one observed in the IPPS base. ${ }^{8}$ These data sources provide alternative benchmarks to discuss measurement errors (see below) and are useful when one has to work with different classifications.

\subsection{IPPS-Related Data Bases}

Insofar as the US IPPS emission coefficients for 1987 were carefully constructed, and in view of the evidence reported by Hettige et al. (2001) suggesting a relative constancy of emissions per unit labor across countries and over time for one pollutant (biological oxygen demand), it is worth checking out to what extent this conjecture holds for $\mathrm{SO}_{2}$ in the EDGAR data and, if so, construct an alternative data base using IPPS coefficients. The boxplots in Fig. 2 provide a first check on the relative constancy of emissions per unit of labor. It represents the distribution of intensities across countries and regions for each one of the seven EDGAR sectors, for either per unit labor or per USD $\mathrm{SO}_{2}$ emissions (to facilitate comparisons, each intensity series has been scaled down by the median, so that when taking logs the interquartile box is approximately centered at zero).

Two stylized patterns emerge. First, emission intensities by sector are more similar across regions than across countries. This is so for both outliers, which disappear when considering

\footnotetext{
8 More precisely, it is assumed that the ratio between the emission intensity of each sector and its employment-weighted mean at the EDGAR category level is identical to the one obtained when applying US IPPS coefficients to the country's specific employment data.
} 
(a) across countries

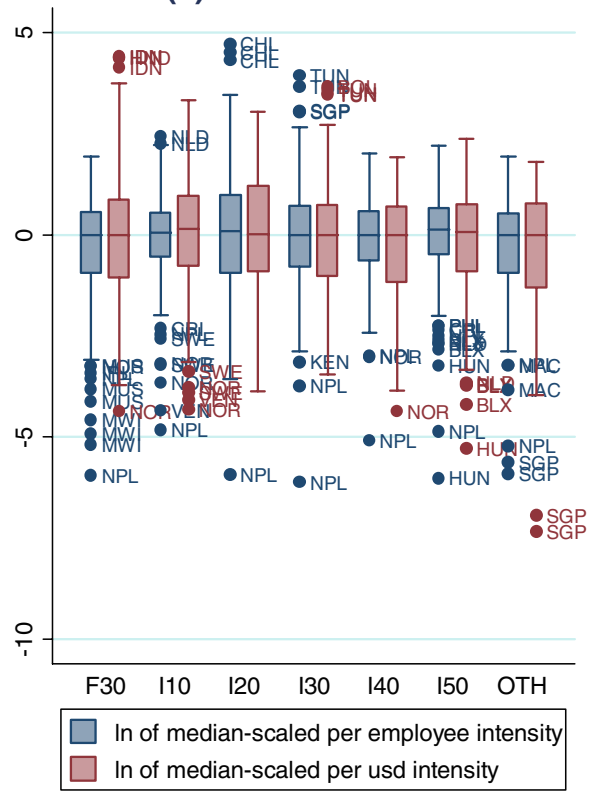

(b) across regions

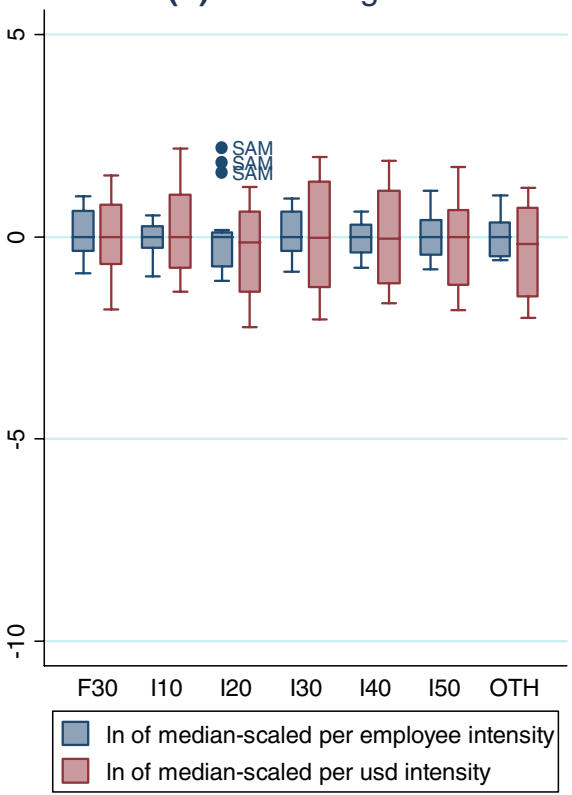

Fig. 2 Boxplots of EDGAR emission intensities (1990-1995-2000) Notes: See Table 1 for a description of EDGAR categories; OTH refers to all other (clean) sectors

Table 3 Coefficient of variation of EDGAR pollution intensities

Note: Figures refer to the unweighted mean over the seven EDGAR sectors

\begin{tabular}{llllll}
\hline & \multicolumn{2}{l}{ Across countries } & & \multicolumn{2}{l}{ Across regions } \\
\cline { 2 - 3 } \cline { 5 - 6 } & $\begin{array}{l}\text { Tonnes per } \\
\text { employee }\end{array}$ & $\begin{array}{l}\text { Kg per 1,000 } \\
\text { USD }\end{array}$ & & $\begin{array}{l}\text { Tonnes per } \\
\text { employee }\end{array}$ & $\begin{array}{l}\text { Kg per 1,000 } \\
\text { USD }\end{array}$ \\
\hline 1990 & 1.28 & 1.54 & 0.53 & 0.99 \\
1995 & 1.49 & 1.69 & 0.66 & 0.96 \\
2000 & 1.56 & 1.86 & 0.79 & 0.98 \\
All 3 years & 1.47 & 1.70 & 0.64 & 0.97 \\
\hline
\end{tabular}

regions (apart from South America for non-ferrous metals which reflects the strong influence of Chile), and for the interquartile range, which is lower across regions, in particular for emissions per unit labor. Second, on the basis of the interquartile range measure, and whatever the sector, emissions per USD exhibit a larger dispersion than emissions per unit of labor.

Because the differences between the two types of intensities is less evident when outlier values are taken into account, Table 3 uses the coefficient of variation-which factors in outliers - as a measure of dispersion. Table 3 estimates confirm that per unit labor intensities exhibit a smaller dispersion than intensities per USD, even though dispersion appears to be increasing over time.

In view of the above and of the lesser dispersion across regions than across countries, as a check, it is arguably justifiable to apply the original IPPS emissions per employee to each 
one of the six regions of the sample in the hope of minimizing errors. ${ }^{9}$ Then, in a second step, these original intensities are scaled to insure that the resulting total of manufacturing emissions per region exactly matches the one reported in EDGAR or obtained from Stern (2006). As a result, total manufacturing emissions of the two versions of the IPPS ad $_{\text {database }}$ are by construction strictly identical to those obtained for the corresponding versions of the EDGAR $_{\mathrm{da}}$ database. The same logic is applied to construct the remaining two databases of Table 2 (IPPS $\mathrm{aa}$ at a more aggregated and IPPS $\mathrm{dd}$ at a more disaggregated level). ${ }^{10}$ Even though we believe that IPPS $_{\text {ad }}$ is the most reliable database amongst the IPPS-related ones

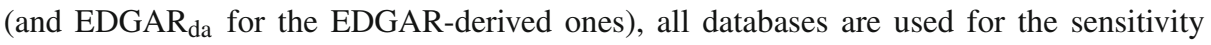
analysis in Sect. 4.

\section{Decomposing Changes in $\mathrm{SO}_{2}$ Emissions: A first Round}

Assume emissions $(E)$, are a joint product with gross output $(X)$. Our decomposition is further guided by the available data which includes in addition, value-added $(Q)$, and labor $(L)$. A general relation between emissions and production for sector $i$ can then be summarized as:

$$
E_{i}=G_{i}\left[X_{i}\left(Q_{i}\left(L_{i}\right)\right)\right]
$$

In theoretical contributions (see e.g. Brock and Taylor 2005), pollution coefficients are usually defined with respect to value added or output i.e. $\beta_{i}=E_{i} / X_{i}$ or $\widetilde{\beta}_{i}=E_{i} / Q_{i}$. In the context of cross-country comparisons over time, this raises the issue of the choice of price and exchange rate indices.

The decomposition of the evolution of "worldwide" $\mathrm{SO}_{2}$ emissions into scale, composition and technique effects is done in two rounds. To minimize the use of questionable data, we start the decomposition by linking emissions directly to employment. Thus we are assuming implicitly that labor productivity and value-added per unit of output are constant avoiding the need to bring in cross-country comparisons in a common currency. In a second round, Sect. 5.1 links emissions to value-added and gross output bringing the decomposition closer to the discussion of the scale, composition and technique effects found in theoretical contributions.

\subsection{Measuring Scale, Composition and Technique Effects}

Let then $L_{k i t}$ represent employment in activity $k$ in country $i$ in year $t, \gamma_{k i t}$ emission intensity per unit of labor and aggregate emissions at the sample-wide level. Then, emissions at the sector, country and global levels are given by:

$$
E_{k i t}=L_{k i t} \gamma_{k i t} ; E_{k t}=\sum_{k} L_{k i t} \gamma_{k i t} ; E_{k t}=\sum_{k} \sum_{i} L_{k i t} \gamma_{k i t}
$$

\footnotetext{
9 We also experimented with an alternative based on fitting a regression of emission intensities on a time trend and per capita and per capita GDP squared, systematically obtaining a poor fit leading us to abandon this alternative route.

10 Data bases below the diagonal reflect the between-country and between-sector variation in EDGAR data, while those above reflect the between-sector variation in the IPPS coefficients, and either the EDGAR or STERN-based between-country variation. Finally for both sets of databases, the temporal variation is either based on EDGAR or STERN, depending on which database has been used as the scaling benchmark.
} 
Let $\theta_{i t}^{E_{t}} \equiv\left(E_{i t} / E_{t}\right)$ denote the share of country in the world labor force, $\theta_{k i t}^{L_{i t}} \equiv\left(L_{k i t} / L_{i t}\right)$ the share of sector $k$ in country $i$ 's labor force and $\theta_{i t}^{E_{t}} \equiv\left(E_{i t} / E_{t}\right)$ the corresponding emission share for country. Then, by total differentiation of the last equation in (0.2), $\mathrm{SO}_{2}$ growth in emissions can be decomposed into the following expression (with a "“" over a variable denoting its growth rate):

$$
\hat{E}_{t}=\hat{L}_{t}+\sum_{i} \theta_{k i t}^{E_{t}}\left(\hat{\theta}_{i t}^{L_{t}}\right)+\sum_{i} \sum_{k} \theta_{k i t}^{E_{t}}\left(\hat{\theta}_{k i t}^{L_{i t}}\right)+\sum_{i} \sum_{k} \theta_{k i t}^{E_{t}}\left(\hat{\gamma}_{k i t}\right)
$$

In (0.3), the first term on the RHS is the scale effect. The second term measures the betweencountry effect and will be positive if countries with the largest emission shares tend to grow faster (in terms of labor shares) since the sum of shares is equal to unity. Likewise, the third term measures the between-sector effect within a country and will be positive if dirty industries have higher employment growth. Finally, the fourth term measures the technique effect.

\subsection{Results}

When implementing (0.3), interaction terms (not shown here since they are assumed to be negligible for small changes) are attributed proportionately across each one of the four terms. Note also the following: (i) up to small differences reflecting the attribution of the interaction terms, the scale effect will be the same across all data bases since the same employment data are used throughout; (ii) likewise, by construction, total emissions are the same across sectoral and country aggregations and for the 10 year period covered here equal either to $-9.9 \%$ (Stern estimates in Table 4) or to $+9.2 \%$ (EDGAR estimates $=$ non-adjusted estimates in Table 4). These limitations in the data have the following consequences. First, differences in estimates across data sets are attributable to differences in the relative importance given to the two composition effects and to the technique effect. Second, since like the scale effect, the two composition effects are drawn from the same TPP data base, the differences in total estimates (19.1\%) are projected into differences in technique effects (about 20\% difference in technique effect between the two base estimates).

Table 4 concentrates on the preferred estimates coming from the EDGAR $_{\mathrm{da}}$ data set, with 62 countries and 7 sectors, leaving to Sect. 4.3 the discussion over alternatives (IPPSderived data sets and/or other aggregation levels). Over the 1990-2000 period, results are quite similar for the scale (around 10\%) and the two composition effects (around minus 5\%), whether intensities are scaled down to STERN levels or not. The major difference comes from the technique effect, which is negative (close to - 15\%) for STERN-adjusted emissions

Table $4 \mathrm{SO}_{2}$ emissions: scale, composition and technique effects (in \%; Preferred database, STERN-adjusted or Non-adjusted intensities)

\begin{tabular}{lccccccc}
\hline & \multicolumn{3}{l}{ STERN-adjusted intensities } & & \multicolumn{3}{l}{ Non-adjusted intensities } \\
\cline { 2 - 3 } \cline { 7 - 8 } & $1990-1995$ & $1995-2000$ & $1990-2000$ & & $1990-1995$ & $1995-2000$ & $1990-2000$ \\
\hline Scale effect & 5.8 & 3.9 & 9.6 & & 6.3 & 4.0 & 10.5 \\
Betw. country & -1.5 & -1.9 & -2.4 & & -1.0 & -1.5 & -3.1 \\
Betw. sector & -2.7 & 0.3 & -3.0 & & -3.2 & -1.0 & -4.8 \\
Technique & -4.1 & -10.0 & -13.9 & & 11.2 & -5.1 & 6.6 \\
Total effect & -2.4 & -7.6 & -9.9 & & 13.3 & -3.6 & 9.2 \\
\hline
\end{tabular}



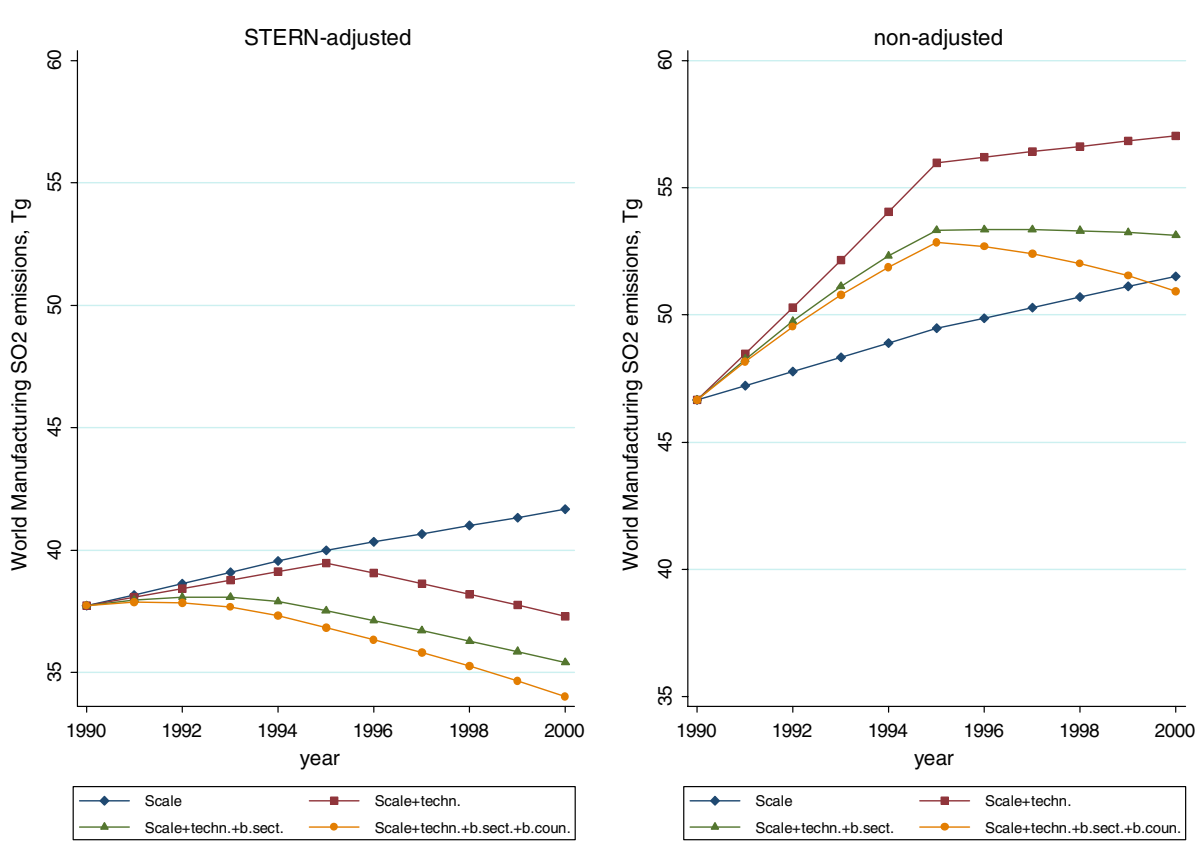

Fig. 3 Global manufacturing $\mathrm{SO}_{2}$ emissions (1990-2000)

but positive (around 5\%) for non-adjusted ones. This leads to a sharp contrast in terms of total emissions, which are decreasing in the STERN-adjusted case and slightly increasing in the other case.

However, differences may be smaller than they appear. When splitting the nineties into two sub-periods, it turns out that the decomposition pattern is quite similar between the second sub-period (1995-2000) for non-adjusted intensities and the first sub-period (1990-1995) for STERN-adjusted ones, as if it just took a 5-year lag for the same trend to be reflected in the non-adjusted data set. This lagged response is further confirmed by Fig. 3, which reports the evolution of world manufacturing $\mathrm{SO}_{2}$ emissions when introducing one by one the four effects contributing to total emissions. ${ }^{11}$

If only scale effects had been at work, emissions would have increased whatever the data set. Adding the technique effect leads to lower (larger) emissions in the case of STERN (non)-adjusted intensities, while composition effects unambiguously decrease total emissions. Eventually, global emissions tend to decrease, whether over the whole decade or during the second sub-period only. This trend reflects the adoption of greener production techniques in the majority of large polluting countries. The 5-year lag between the two data sets is due to the methodology used by Stern (2006), which allows for a better control of abatement activities in developing countries [see discussion in Appendix 2 (supplementary material)].

11 Figures between base years are obtained by linear interpolation. Total emissions can be written as $E_{t}=$ $L_{t} \sum_{i} \sum_{k} \theta_{i t}^{L_{t}} \theta_{k i t}^{L_{i t}} \gamma_{k i t}$. The curve representing the scale effect takes only world manufacturing employment $\left(L_{t}\right)$ into account, freezing all the other terms of the double sum at their 1990 levels. This assumption is further relaxed term by term. 
In sum, the above results suggest that the nineties witnessed a structural shift towards cleaner activities and a shift of activities towards cleaner countries (see Sects. 5 and 6 for a discussion). This has been accompanied by more abatement activities, which are better captured by the Stern-adjusted intensities (probably the best estimates at hand), and have contributed to a substantial decline in emissions in spite of the scale effect.

\subsection{Robustness to Alternative Databases}

As a robustness check, Table 5 contrasts the preferred estimates presented above based on $\left(E_{D G A R}\right.$ da $)$ with those obtained when aggregating across sectors [similar results are obtained for non-adjusted emissions, see Table A6 in the Appendix (in supplementary material)]. Comparing lines 1 and 2 or 5 and 6 shows very little difference. Thus emission intensities are quite homogenous inside the 7 EDGAR sectors and disaggregating further to the 28 ISIC sectors does not change the picture. This is not surprising given that in the EDGAR classification dirty sectors are considered explicitly, while all clean sectors, which have smaller differences in intensities, are lumped together into one sector.

However aggregating across countries (comparing lines 2 and 3 or 4 and 5) does increase the magnitude of the negative between-country composition effect. This suggests that the within-region structural shift has been in the opposite direction to the global one, i.e. intraregional production has shifted on average towards the dirtiest countries within each region. Thus, working at the aggregated level in terms of geographic entities may lead to a small overestimation of the composition effects.

Comparing EDGAR and IPPS data sets at the same level of aggregation (i.e. lines 1 and 4 or 3 and 6) does not alter the between-country effect but leads to a stronger technique effect in the case of EDGAR (or equivalently to a stronger between-sector effect in the case of IPPS) which is to be expected since EDGAR is the data set that includes temporal variation in emission-intensity data.

In sum, while there are some differences when weights are altered, these are small. Overall, as cross-country and time variation of emission intensities is basically derived from the EDGAR database, our preferred set of intensities is EDGAR $_{\mathrm{da}}$ (line 2 of Table 5), which matches most closely the original data source.

Table $5 \quad \mathrm{SO}_{2}$ emissions scale, composition and technique effects across databases (1990-2000, STERNadjusted total emissions)

\begin{tabular}{|c|c|c|c|c|c|c|c|c|}
\hline & & \multicolumn{2}{|c|}{ Database } & \multicolumn{4}{|c|}{ 1990-2000 Growth decomposition (\%) } & \multirow[b]{2}{*}{ Total } \\
\hline & & Entities & Sectors & $\begin{array}{l}\text { Scale } \\
\text { effect }\end{array}$ & $\begin{array}{l}\text { Between } \\
\text { country }\end{array}$ & $\begin{array}{l}\text { Between } \\
\text { sector }\end{array}$ & Technique & \\
\hline 1 & EDGAR & 62 & 28 & 9.6 & -2.5 & -2.7 & -14.3 & -9.9 \\
\hline 2 & EDGAR $_{\text {da }}$ & 62 & 7 & 9.6 & -2.4 & $-\mathbf{3 . 0}$ & -13.9 & -9.9 \\
\hline 3 & EDGAR $_{\mathrm{aa}}$ & 6 & 7 & 9.5 & -4.4 & -2.4 & -12.6 & -9.9 \\
\hline 4 & IPPS $_{\mathrm{dd}}$ & 62 & 28 & 9.5 & -2.4 & -3.7 & -13.3 & -9.9 \\
\hline 5 & IPPS $_{\mathrm{ad}}$ & 6 & 28 & 9.5 & -4.4 & -4.4 & -10.5 & -9.9 \\
\hline 6 & IPPS $_{\mathrm{aa}}$ & 6 & 7 & 9.5 & -4.4 & -4.2 & -10.8 & -9.9 \\
\hline
\end{tabular}

Note: The line in bold characters indicates the preferred database 


\section{Alternative Decompositions}

Any decomposition exercise entails decisions, some of which are suggested by the data, others that may seem arbitrary. This section presents two other decompositions. The first (Sect. 5.1) carries out the decomposition using gross output and value-added instead of labor as scaling factor. The second (Sect. 5.2) explores the sensitivity of results to defining the 'between sector' effect at the aggregate level (and the 'between country' effect at the disaggregated level).

\subsection{Factoring in Productivity Changes ${ }^{12}$}

We now report results when using either value added or output as scaling variables. In Eq. 0.3, $L$ and $\gamma$ now represent, respectively value added (or output) and emission intensity per dollar of value added (or output).

Under this alternative, price indices are needed for comparisons across sectors and exchange rate indices are needed for cross-country comparisons. Several alternatives were tested, depending on the type of price indices and exchange rates considered. ${ }^{13}$ We report here the preferred set of estimates which are based on the market exchange rate and a sector-specific deflator at the world level extracted from the TPP database (see Appendix 4 for further details in supplementary material).

Table 6 contrasts these new results with the earlier ones and reports also the range of results obtained when changing either the price deflator or the exchange rate. Three main differences with our earlier results emerge: first the scale effect becomes larger, second, as expected, the magnitude of the negative technique effect is magnified; third, there is a large change in the 'between-country' effect and practically no change in the 'between-sector' effect. Finally, these broad differences are quite robust to the choice of price indices and exchange rates.

Three effects interact in determining the pattern of results in Table 6. First, the difference in scale effects in column 1 reflects the combination of a worldwide (manufacturing) increase in labor productivity ([13.7-9.5]), and an increase in the round-aboutness of production activities (i.e. an increase in the gross-output to value-added ratio [22.2-13.7]) Second, is an 'overall' labor productivity effect that would occur in a one-sector, one-country world. In such a situation, the increase in the scale effect in rows 2 and 3 would be reflected by an equivalent (but of opposite sign) technique effect in column 4, i.e. increases in labor productivity would be matched one-for-one by decreases in emissions intensities. Third are the composition effects that result from a multi-country, multi-sector world. Since the 'betweensector' effect is almost identical regardless of the choice of scaling, we concentrate on the determinants of the differences in 'between-country' effects.

As explained in Appendix 5 (in supplementary material), the composition effects include two dimensions: first labor reallocations (across sectors and countries); and second the distribution of productivity gains across sectors and countries. These effects are reported in Table 7. Overall, it turns out that the two sources of differences reinforce each other. For example, the difference in the 'between-country' effect when comparing scaling by employment

\footnotetext{
12 We thank an anonymous referee for suggesting this analysis.

13 As argued by Levinson (2007) in the case of the US, the use of an economy-wide price deflator would lead to overstate the technique effect in pollution abatement because of the increase in the relative price of highly polluting sectors like petroleum, while the use of industry-specific deflators will tend to overstate the green shift towards cleaner products because of the changing nature of the products in relatively clean industries like computers.
} 
Table 6 Results with alternative scale measures (1990-2000 Growth decomposition, \%)

\begin{tabular}{|c|c|c|c|c|c|c|}
\hline & Scale measure & $\begin{array}{l}\text { Scale } \\
\text { effect (1) }\end{array}$ & $\begin{array}{l}\text { Between } \\
\text { country (2) }\end{array}$ & $\begin{array}{l}\text { Between } \\
\text { sector (3) }\end{array}$ & $\begin{array}{l}\text { Technique } \\
\text { (4) }\end{array}$ & $\begin{array}{l}\text { Total } \\
(5)\end{array}$ \\
\hline 1 & $\begin{array}{l}\text { Employment } \\
\quad \text { (from Table } 5 \\
\text { row 2) }\end{array}$ & 9.5 & -2.4 & -3.0 & -13.9 & -9.9 \\
\hline 2 & $\begin{array}{l}\text { Value-added } \\
\text { (range) }\end{array}$ & $13.7(13.5 / 20.7)$ & $24.9(15.54 / 24.9)$ & $-4.0(-9.1 /-3.2)$ & $-44.6(-45.4 /-37.6)$ & -9.9 \\
\hline 3 & Output (range) & $22.2(21.3 / 30.4)$ & $21.1(10.8 / 21.1)$ & $-2.8(-7.5 /-1.9)$ & $-50.4(-51.6 /-43-9)$ & -9.9 \\
\hline
\end{tabular}

Note: Deflation of current USD values by a world-average sector-specific price index; range in parenthesis from combining different types of price indices and exchange rates (see Appendix 4 for details in supplementary material)

Table 7 Accounting for productivity changes (1990-2000 growth decomposition, \%)

\begin{tabular}{llllll}
\hline Factors compared & Scale effect & Between country & Between sector & Technique & Line total \\
\hline $\begin{array}{c}\text { Employment-value added } \\
1 \quad \text { Total difference (line } \\
\text { 1-line 2, Table 6) } \\
\text { of which: }\end{array}$ & -4.2 & -27.4 & 1.0 & 30.6 & 0 \\
$2 \quad \begin{array}{c}\text { Sources of global } \\
\text { productivity gains }\end{array}$ & -17.5 & -0.1 & 21.7 & 4.2 \\
$3 \quad \begin{array}{c}\text { Clean bias of } \\
\text { productivity gains }\end{array}$ & -10.0 & 1.0 & 8.9 & 0 \\
$\begin{array}{c}\text { Employment-gross output } \\
4 \quad \text { Total difference (line } \\
\text { 1-line 3, Table 6) } \\
\text { of which: }\end{array}$ & -12.7 & -23.5 & -0.3 & 36.5 & 0 \\
$5 \quad \begin{array}{c}\text { Sources of global } \\
\text { productivity gains }\end{array}$ & -17.5 & -0.5 & 30.7 & 12.7 \\
$6 \quad \begin{array}{c}\text { Clean bias of } \\
\text { productivity gains }\end{array}$ & -6.0 & 0.2 & 5.8 & 0 \\
\hline
\end{tabular}

See Appendix 5 (in supplementary material) for the decomposition formulas

${ }^{a}$ A positive (negative) entry means a bias towards clean (dirty) sectors

with scaling by value-added [-27.4] comes from manufacturing labor being reallocated towards less productive countries $[-17.5]$ and productivity gains being large in 'dirty countries' [-10.0]. Similar decomposition results are obtained when comparing scaling by labor with scaling by gross output. The small magnitude for the 'between sector' effect reflects the combination of uniform productivity changes and labor allocations across manufacturing sectors.

In sum, although the dubious quality of price deflators and exchange rates make it hard to articulate precise figures, this subsection suggests that the negative between-country effect identified in Table 5 must be taken with caution. As soon as differences in labor productivity are controlled for, it turns out that composition effects across countries have had a positive contribution to the growth in world $\mathrm{SO}_{2}$ emissions, not a negative one. This is so because over the nineties, on average, less productive countries have been gaining labor-manufacturing shares, and because productivity gains have been larger in the dirtiest countries. 
Table 8 Alternative decompositions of the composition effect (1990-2000, \%)

\begin{tabular}{|c|c|c|c|c|c|c|}
\hline \multirow[t]{2}{*}{ Scale measure } & \multicolumn{3}{|c|}{ Between-country effect } & \multicolumn{3}{|c|}{ Between-sector effect } \\
\hline & $\begin{array}{l}\text { Original } \\
\text { (1) }\end{array}$ & $\begin{array}{l}\text { Alternative } \\
\text { (2) }\end{array}$ & $\begin{array}{l}\text { Average } \\
(3)=0.5^{*}[(1)+(2)]\end{array}$ & $\begin{array}{l}\text { Original } \\
\text { (4) }\end{array}$ & $\begin{array}{l}\text { Alternative } \\
\text { (5) }\end{array}$ & $\begin{array}{l}\text { Average } \\
(6)=0.5 *[(4)+(5)]\end{array}$ \\
\hline Employment & -2.4 & -6.5 & -4.5 & -3.0 & 0.8 & -1.9 \\
\hline Value-added & 24.9 & 24.1 & 24.5 & -4.0 & -2.8 & -3.4 \\
\hline Output & 21.1 & 19.7 & 20.4 & -2.8 & -1.3 & -2.0 \\
\hline
\end{tabular}

Notes: Columns (1) and (4) are reported results from Table 6 (between effect defined across countries); columns (2) and (5) are the corresponding figures when the between effect is defined across sectors; columns (3) and (6) are simple averages of the two preceding ones

\subsection{A More Balanced Decomposition Formula?}

The basic decomposition formula used until now defines arbitrarily the between-country effect at the aggregate level (country shares) and the "between-sector" effect at the disaggregated level (country-specific sector shares). This means that the "between-sector" effect could also have been called a "within-country" effect. Apart from terminological issues, this also means that the opposite convention could have been proposed, defining the betweensector effect at the aggregate level and the "between-country" effect (in fact a "within-sector" effect) at the disaggregated level, as in the following expression:

$$
\hat{E}_{t}=\hat{L}_{t}+\sum_{k} \theta_{k i t}^{E_{t}}\left(\hat{\theta}_{k t}^{L_{t}}\right)+\sum_{i} \sum_{k} \theta_{k i t}^{E_{t}}\left(\hat{\theta}_{k i t}^{L_{k t}}\right)+\sum_{i} \sum_{k} \theta_{k i t}^{E_{t}}\left(\hat{\gamma}_{k i t}\right)
$$

Results obtained on the basis of this alternative growth decomposition formula are reported in columns (2) and (5) of Table 8. But for small differences due to interaction terms, the formula used (either Eq. 0.3 or 0.4 ) should not affect the magnitude of the scale and technique effects, which are therefore not reported in the table. Moreover, as the choice between the two versions is an arbitrary one, columns (3) and (6) report the average value of each effect.

Globally, differences are rather small, in particular when output or value added are used as scaling variables. Differences are somewhat larger when using employment, and suggest that the shift towards cleaner countries (and cleaner sectors) might have been understated (overstated) by the original approach. However the differences are not large and the average outcomes are perfectly in line with the other results commented so far.

\section{Correlates of the composition Effect $^{14}$}

This section explores some of the correlates of the composition effect identified above. This is only a first exploration limited by data availability for manufacturing sectors over a large number of countries. Several driving factors can be identified. First, composition effects may be induced by shifts in relative preferences, leading to increased demand for certain goods. Second, composition effects might be affected by the trade orientation of the sector, here captured by trade intensity, reflecting patterns of specialization across countries. Third,

\footnotetext{
14 We thank an anonymous referee for having suggested this extension. A similar exercise regarding the technique effect was discarded because of the lack of available indicators regarding environmental and industrial policies at a sufficiently disaggregated level.
} 
relative prices of goods might change because of other reasons, for instance changes in the cost structure of producers which can lead to shifts in relative supplies.

Besides finding appropriate proxies to capture these channels, any exercise is complicated by the fact that these channels are interdependent; as for instance changes in preferences would also lead to changes in relative prices. We explore these channels in a single equation framework that basically seeks to establish the relative importance of changes in relative prices vis-à-vis changes in trade intensity in shaping composition effects. ${ }^{15}$ In this set-up, the two components of the contribution of country $i$ sector $k$ to the overall composition effect are considered separately. ${ }^{16}$ The explanatory variables are the growth of the index of revealed comparative advantage (RCA) and of the price index and all specifications include country and sector dummies. ${ }^{17}$

Results are reported in Table 9. Columns (1) and (2) report results with respect to the growth rates in economic activity shares. As expected, whatever the scaling factor (labor or value-added), both variables are positively correlated with scale. RCA growth has a positive and highly significant effect in all specifications and the effect is slightly stronger for valueadded shares than for labor shares. The price index growth rate has a similar impact although it is not significant on labor shares. The respective role of the two regressors is clarified by two additional statistics: standardized coefficients and the decomposition of Fields (2003). Looking at standardized coefficients, the labor share growth rate increases by 0.4 standard deviations following an increase of the RCA growth rate by one standard deviation, while the corresponding increase is 0.2 in the case of the price index growth rate. Hence the relative importance of the two variables is roughly two to one in the labor case, while it is of similar magnitude in the case of value-added (standardized coefficient of 0.3). The Fields decomposition reports how much of the total variance is explained by our explanatory variables. ${ }^{18}$ It turns out that $17 \%$ of the total sum of square of labor growth is accounted for by RCA growth, while only $5 \%$ are accounted for by changes in relative prices. Concerning value-added shares, we find that roughly $11 \%$ of the total sum of squares can each time be attributed to RCA growth and price changes.

The remaining two columns of Table 9 give the corresponding results when emission shares are used. Significant impacts only appear when taking the log of the explained variable (most of these shares are clustered between 0 and 0.05), and they are negative for both RCA and prices growth rates. Regarding their relative importance, the price index growth rate seems to have more explanatory power than the RCA growth rate on initial emission shares.

In short, even if we do not find a significant impact of prices or trade on the total composition effect over the sample period, we identify significant correlates on the two constitutive components of this effect. On the one hand, and quite intuitively, we find that the general allocation of labor and production at the world-wide level tends to follow price increases

\footnotetext{
15 Changes in preferences are not identified directly over the relatively short time span of 10 years in addition to what would be captured by sector dummies and relative prices.

16 Using the product of the growth rate in economic activity and emission shares does not give any significant results. An intuitive explanation for this is given by the opposite regression coefficients found for the two separate components (see Table 9).

17 Explanatory variables are probably not exogenous and the RCA index captures both trade policy and comparative advantage factors. The RCA index for a sector country combination is the ratio of the share of sector $k$ in the exports of country $i$ to the share of sector $k$ in total world (sample) exports.

18 Results for the more general Shapley decomposition (Shorrocks 1999) are fairly similar but are only available for specifications without country dummies. See Israeli (2007) for a comparison between the two methods.
} 
Table 9 Determinants of the composition effect

Dependent variable:

\begin{tabular}{|c|c|c|c|c|}
\hline & \multicolumn{2}{|c|}{ Growth in economic activity } & \multicolumn{2}{|c|}{ Emission share } \\
\hline & $\begin{array}{l}\hat{\theta}_{k i t}^{L_{t}} \\
\text { labor (1) }\end{array}$ & $\begin{array}{l}\hat{\theta}_{\text {kit }}^{Q_{t}} \\
\text { value-added (2) }\end{array}$ & $\begin{array}{l}\theta_{k i t}^{E_{t}} \\
\text { (3) }\end{array}$ & $\begin{array}{l}\operatorname{In}\left(\theta_{k i t}^{E_{t}}\right) \\
\text { (4) }\end{array}$ \\
\hline \multicolumn{5}{|l|}{ RCA growth rate: } \\
\hline Estimated coefficient & $0.008 * * *$ & $0.011 * * *$ & $-0.000 * * *$ & $0.003 * * *$ \\
\hline Robust standard error & 0.0002 & 0.0004 & 0.000 & 0.001 \\
\hline Standardized coefficient ${ }^{\mathrm{a}}$ & 0.424 & 0.341 & -0.027 & -0.056 \\
\hline Fields decomposition ${ }^{\mathrm{b}}$ & 0.174 & 0.11 & 0.0007 & 0.012 \\
\hline \multicolumn{5}{|l|}{ Price index growth rate: } \\
\hline Estimated coefficient & $0.199^{*}$ & $0.484 * *$ & -0.0001 & $-0.255^{* * *}$ \\
\hline Robust standard error & 0.104 & 0.148 & 0.0001 & 0.061 \\
\hline Standardized coefficient ${ }^{\mathrm{a}}$ & 0.224 & 0.331 & -0.014 & -0.096 \\
\hline Fields decomposition ${ }^{\mathrm{b}}$ & 0.053 & 0.107 & 0.0008 & 0.020 \\
\hline R-squared & 0.49 & 0.44 & 0.69 & 0.86 \\
\hline Number of observations & 423 & 423 & 423 & 415 \\
\hline
\end{tabular}

All specifications include a complete set of country and sector dummies which increase the explanatory power of the regressions, but have little impact on the estimated values of the other variables

a Standardized coefficients are regression coefficients of standardized variables (with a mean of zero and a standard deviation of 1)

${ }^{\mathrm{b}}$ See text

* Significant at $10 \%$; ** significant at $5 \%$; *** significant at $1 \%$

and export performance as measured by RCAs. On the other hand, the allocation of emission seems to follow a reverse pattern, i.e. price increases and export growth are associated with lower emissions. Note that the decrease in the price of petroleum products during the $90 \mathrm{~s}$ and the high transport costs in polluting sectors are both consistent with this reverse pattern.

\section{Conclusions}

Extracting the best out of the available information, we constructed a set of original databases on $\mathrm{SO}_{2}$ intensities over the nineties, which is consistent with the most recent estimates of national emissions reported by Stern (2006), and allows for the first time to relate manufacturing activity with $\mathrm{SO}_{2}$ emissions taking detailed composition effects into account.

Beyond indicating the importance of the choice of scaling variables in the decomposition, several growth decomposition exercises establish a number of stylized facts that help to identify the driving factors that contributed to the decrease in $\mathrm{SO}_{2}$ emissions during the sample period. First, the scale and technique effects always work in opposite directions while the sign of the composition effect depends on scaling assumptions.

Second, using labor as the scaling factor, both composition effects are negative and rather small in magnitude, adding an additional $5 \%$ to the global decrease in world emissions $(-10 \%$ in total). In other words, a global shift of employment towards cleaner sectors and cleaner countries has contributed to reduce worldwide pollution during the sample period. 
Third, the choice of scaling factor matters suggesting the usefulness of experimenting with several scaling factors whenever possible. When value added or output is used as the scaling factor, the picture changes, with a magnification of the scale and technique effects and a between-country effect that becomes strongly positive. This reflects both the increase in global productivity worldwide and the sources of this productivity gain, namely a shift of output towards low-productivity countries and a bias of productivity gains towards dirty countries. Note that this pattern is perfectly compatible with the employment-based decomposition, because large emerging manufacturing players such as China and India can be simultaneously considered as either clean or dirty depending on intensities being expressed in terms of emissions per unit labor or emissions per dollar. Finally, limited exploration of the correlates of the composition effect, suggests that sectoral price increases and export growth are associated with lower emissions.

All in all, given the available data, it appears that the above-mentioned patterns have been shown to be fairly robust across databases and selection of decomposition methods, but that the choice of scaling variables impacts strongly on the split of the composition effects into its constituent parts.

Acknowledgements Financial support from the Swiss National Science Foundation under research grant No 100012-109926 is gratefully acknowledged. An earlier version of this paper was presented at the ETSG 2006 conference in Vienna. We thank an anonymous referee and conference participants for helpful comments and Werner Antweiler and Robert Elliott for providing us with data and for helpful comments. All remaining errors are our sole responsibility.

\section{References}

Antweiler W, Copeland B, Taylor MS (2001) Is free trade good for the environment?Am Econ Rev 91(4):877_ 908

Brock W, Taylor MS (2005) Economic growth and the environment: a review of theory and empirics. In: Aghion P, Durlauf S (eds) Handbook of economic growth, vol 28, pp 1749-1821

Cole M, Elliott RJR (2003) Determining the trade-environment composition effect: the role of capital, labor and the environment. J Environ Econ Manage 46:363-383. doi:10.1016/S0095-0696(03)00021-4

Fields GS (2003) Accounting for income inequality and its change: a new method with application to the distribution of earnings in the United States. Res Labor Econ 22:1-38

Grossman GM, Krueger AB (1991) Environmental impacts of a North American free trade agreement. NBER Working paper No. 3914

Hettige M, Muthukurama DW (1995) IPPS: the industrial pollution project system. World Bank PRWP 1431

Hettige M, Muthukurama DW (2001) Industrial pollution in economic development: Kuznets revisited. J Dev Econ 62:445-460. doi:10.1016/S0304-3878(00)00092-4

Israeli O (2007) A shapley-based decomposition of the R-Square of a linear regression. J Econ Inequal 5:199212. doi:10.1007/s10888-006-9036-6

Levinson A (2007) Technology, international trade, and pollution from US manufacturing. NBER Working Paper 13616

Nicita A, Olarreaga M (2007) Trade, production and protection, 1976-2004. World Bank Econ Rev 21(1):165171. doi: $10.1093 /$ wber/lhl012

Olivier JGJ, Berdowski JJM (2001) Global emission sources and sinks. In: Berdowski J, Guicherit R, Heij B (eds) The climate system. A.A. Balkema Publishers, Swets \& Zeitlinger Publishers, Lisse, The Netherlands, pp 33-78

Shorrocks AF (1999) Decomposition procedures for distributional analysis: an unified framework based on the Shapley value, Mimeo, University of Essex. Available at http://giganda.komkon.org/ tacik/science/ shapley.pdf

Stern DI (2006) Reversal of the trend in global anthropogenic sulfur emissions. Glob Environ Change 16:207220. doi:10.1016/j.gloenvcha.2006.01.001 